\title{
Management of Acute Liver Failure: A Pediatric Perspective
}

\author{
Heli Bhatt ${ }^{1}$ - Girish S. Rao ${ }^{1}$ \\ Published online: 15 May 2018 \\ (C) Springer Science+Business Media, LLC, part of Springer Nature 2018
}

\begin{abstract}
Purpose of Review Pediatric acute liver failure is a rare, complex, rapidly progressing, and life-threatening illness. Majority of pediatric acute liver failures have unknown etiology. This review intends to discuss the current literature on the challenging aspects of management of acute liver failure.

Recent Findings Collaborative multidisciplinary approach for management of patients with pediatric acute liver failure with upfront involvement of transplant hepatologist and critical care specialists can improve outcomes of this fatal disease. Extensive but systematic diagnostic evaluation can help to identify etiology and guide management. Early referral to a transplant center with prompt liver transplant, if indicated, can lead to improved survival in these patients.

Summary Prompt identification and aggressive management of pediatric acute liver failure and related comorbidities can lead to increased transplant-free survival and improved post-transplant outcomes, thus decreasing mortality and morbidity associated with this potential fatal condition.
\end{abstract}

Keywords Acute liver failure $\cdot$ Pediatric $\cdot$ Multi-organ system failure $\cdot$ Hepatic encephalopathy $\cdot$ Coagulopathy $\cdot$ Liver transplantation

$\begin{array}{ll}\text { Abbreviations } \\ \text { ALF } & \text { Acute liver failure } \\ \text { PALF } & \text { Pediatric acute liver failure } \\ \text { HE } & \text { Hepatic encephalopathy } \\ \text { ICH } & \text { Intracranial hypertension } \\ \text { CE } & \text { Cerebral edema } \\ \text { ICP } & \text { Intracranial pressure } \\ \text { CPP } & \text { Cerebral perfusion pressure } \\ \text { HTS } & \text { Hypertonic saline } \\ \text { CT } & \text { Computerized tomography } \\ \text { MRI } & \text { Magnetic resonance imaging } \\ \text { PT } & \text { Prothrombin time } \\ \text { INR } & \text { International normalized ratio } \\ \text { rFVIIa } & \text { Recombinant factor VIIa } \\ \text { SIRS } & \text { Systemic inflammatory response syndrome } \\ \text { SCr } & \text { Serum creatinine }\end{array}$

This article is part of the Topical Collection on Gastrology

Girish S. Rao

gsrao@iu.edu

1 Section of Pediatric Gastroenterology, Hepatology and Nutrition, Riley Hospital for Children, Indiana University School of Medicine, Indiana University, 705 Riley Hospital Drive, ROC 4210, Indianapolis, IN 46202, USA

$\begin{array}{ll}\text { RRT } & \text { Renal replacement therapy } \\ \text { CRRT } & \text { Continuous renal replacement therapy } \\ \text { LT } & \text { Liver transplantation } \\ \text { KCHC } & \text { King's College Hospital Criteria } \\ \text { MELD } & \text { Model for End-stage Liver Disease } \\ \text { SOFA } & \text { Sequential organ failure assessment } \\ \text { PELD } & \text { Pediatric End-stage Liver Disease }\end{array}$

\section{Introduction}

Acute liver failure (ALF) is a complex, uncommon illness which can rapidly progress to multisystem organ failure and death. It is characterized by acute hepatocellular injury or death, leading to rapid loss of hepatocellular function resulting in multisystem involvement and, eventually, failure. In adults, it was initially characterized by signs of severe hepatic dysfunction, including jaundice and coagulopathy, accompanied by development of hepatic encephalopathy within 8 weeks of onset of the signs and symptoms of liver disease [1]. The inability to assess the age-appropriate mental status and the exact duration of illness in children has made it challenging to apply this definition to children $[2 \bullet \bullet, 3]$. Pediatric acute liver failure (PALF) can be defined as: 
- Biochemical evidence of acute liver injury in a child with no known evidence of chronic liver disease along with at least one of the following

- $\quad$ INR $>1.5$, not corrected with vitamin $\mathrm{K}$ supplementation, with encephalopathy

- $\quad$ INR $>2.0$, not corrected with vitamin K supplementation, without encephalopathy.

Pediatric ALF differs significantly from ALF in adults in both clinical presentation and etiologic spectrum. The diagnosis, evaluation, and management of this rare but complex syndrome require aggressive diagnostic evaluation along with close monitoring, anticipating, and managing the multisystem complications that happen secondary to ALF to prevent organ failure, transplantation, and death.

\section{Etiology and Diagnostic Evaluation}

The incidence of ALF in children is largely unknown. ALF accounts for about $10-15 \%$ of pediatric liver transplants performed annually in the USA [4•]. Up to 40-50\% of PALF is of indeterminate etiology, partly owing to a lack of thorough diagnostic evaluation $[5,6]$. In infants, metabolic and infectious etiologies are more common, with herpes simplex virus being the most common infectious etiology [7]. In adolescents, drug-induced liver injury and autoimmune hepatitis are more common. In developing countries, infectious etiologies dominate with hepatitis A viral infection being the most common infection [5]. Acetaminophen overdose accounts for more than $75 \%$ of drug-induced ALF [3]. Diagnostic evaluation for the PALF should be tailored according to age of presentation (Table 1). Preference should be given to diagnosis of diseases that have targeted therapies, that are preventable in future, or where transplant would be contraindicated.

All children with ALF should undergo systematic evaluation for identification of a cause of liver failure along with assessment of liver injury and dysfunction. A comprehensive history with emphasis on onset of symptoms, changes in mental status, exposure to infectious contacts, blood transfusions, use of medications, and/or family history of liver disease, infant death, autoimmune conditions, and consanguinity should be obtained. Complete physical examination along with a thorough neurological status evaluation is vital. Laboratory evaluation of acute liver failure includes assessment of liver function and liver injury in addition to assessment of overall functioning of all the vital organs of the body. This would include a comprehensive metabolic panel, liver enzymes, total and fractionated bilirubin, gammaglutamyl transferase, prothrombin time with international normalized ratio, reliable serum ammonia level, and a complete blood count $[8,9]$. Etiologic testing for age-appropriate causes of ALF should be tailored according to presentation of illness, history, physical exam, and clinical course to optimize the amount of blood drawn and number of tests ordered [3, 8]. Ultrasound of the abdomen with Doppler should be a part of evaluation for all patients [9]. Further imaging studies like CT, MRI, and/or MRCP should be considered [2••]. Liver biopsy should be performed early in cases of unclear diagnosis, not only for assessment of etiology but also to help assess patient's prognosis. Trans-jugular approach should be used for liver biopsy in the setting significant coagulopathy to prevent complications. One should be cautious in interpreting the level of necrosis in liver biopsy specimens as injury may not be uniform throughout the liver [10]. (Table 1).

\section{Management}

Approach to Management Management of PALF is challenging due to multi-organ system involvement necessitating multidisciplinary approach and potential for rapid deterioration. Patients with suspected PALF should undergo immediate evaluation. Close collaboration between pediatric hepatologist, intensivist, transplant surgeons, neurologist, nephrologist, and/or metabolic disease specialists is crucial. Pediatric patients demonstrating signs of worsening coagulopathy and/or altered mental statues should be monitored in intensive care unit where frequent neurological, cardiorespiratory, and laboratory monitoring can be performed. Once the initial evaluation has been performed and patient has been stabilized, further patient management should be along the path of monitoring and supporting the patient and organ systems, identifying and treating complications, age-appropriate diagnostic evaluation, and optimizing treatment to maximize health and survival [3] (Table 2).

Intensive care unit plays a vital role by supporting the failing organs which in turn helps recovery as well as clinical stability for further interventions, if needed. Advances in critical care medicine and management strategies have contributed significantly towards decreasing mortality in ALF in adults [11]. Similar strategies should also be assessed to help improve outcomes in PALF [2••]. Early transfer to a transplant center is of utmost importance.

Central Nervous System-Hepatic Encephalopathy and Cerebral Edema Hepatic encephalopathy (HE) is a progressive but potentially reversible neuropsychiatric syndrome that occurs as a complication of liver failure. The clinical features of HE can range from subtle cognitive or motor deficits to irritability to overt cerebral edema leading to coma. Pathogenesis of hepatic encephalopathy is not completely understood. Hyperammonemia, increased cerebral blood flow, and augmented inflammatory response are pivotal in causing the increased intracranial pressure [12]. Glutamine is broken down into ammonia and glutamate by glutaminase in the enterocytes. 
Table 1 Causes of pediatric acute liver failure - age based with diagnostic evaluation

\begin{tabular}{|c|c|c|}
\hline Age & Most common causes & Diagnostic evaluation \\
\hline \multirow[t]{6}{*}{ All patients } & Idiopathic or indeterminate (incomplete evaluation) & $\begin{array}{l}\text { Liver function tests: AST, ALT, GGT, alkaline } \\
\text { phosphatase, fractionated bilirubin, albumin, total } \\
\text { protein) }\end{array}$ \\
\hline & Drug toxicity or ingestions & $\begin{array}{l}\text { Coagulation factors and profile: PT-INR, aPTT, } \\
\text { fibrinogen, factors V, VII, VIII }\end{array}$ \\
\hline & Infectious causes & Serum ammonia level and blood gas \\
\hline & Autoimmune hepatitis & Complete blood count with platelets and differential \\
\hline & Metabolic causes & $\begin{array}{l}\text { Complete metabolic panel including electrolytes, } \\
\text { BUN, creatinine, blood glucose, calcium, } \\
\text { magnesium and phosphorus }\end{array}$ \\
\hline & Other causes & $\begin{array}{l}\text { Imaging studies: ultrasound liver with Doppler study } \\
\text { Tissue diagnosis: liver biopsy; muscle biopsy as } \\
\text { indicated }\end{array}$ \\
\hline \multirow[t]{3}{*}{ Infants $\leq 1$ year } & $\begin{array}{l}\text { Idiopathic or indeterminate } \\
\text { Infectious (HSV } 1 \text { and } 2 \text {-most common, enterovirus, } \\
\text { adenovirus, hepatitis B, hepatitis C, EBV, CMV, } \\
\text { HHV 6, parvovirus, etc.) }\end{array}$ & $\begin{array}{l}\text { Viral PCR for EBV, CMV, enterovirus, adenovirus, } \\
\text { HHV-6, HSV } 1 \text { and 2, parvovirus. Viral hepatitis } \\
\text { serology including anti-HAV IgM, HBsAg, } \\
\text { anti-HBe IgM and IgG, anti-HCV, and anti-HEV }\end{array}$ \\
\hline & $\begin{array}{l}\text { Metabolic (fatty acid defects, mitochondrial defects, } \\
\text { galactosemia, tyrosinemia, neonatal } \\
\text { hemochromatosis, etc.) }\end{array}$ & $\begin{array}{l}\text { Serum lactate, pyruvate, amino acid profile, carnitine } \\
\text { profile, acyl-carnitine profile, ferritin, iron, TIBC; urine } \\
\text { amino acid/organic acid profile, urine succinylacetone }\end{array}$ \\
\hline & $\begin{array}{l}\text { Other diseases - congenital heart defects, accidental } \\
\text { drug overdose or ingestion }\end{array}$ & Serum acetaminophen level, urine toxicology screen \\
\hline \multirow[t]{5}{*}{ Pre-adolescent } & Idiopathic or indeterminate & \\
\hline & $\begin{array}{l}\text { Drug toxicity or accidental ingestion (acetaminophen, } \\
\text { acetylsalicylic acid, valproic acid, etc.) }\end{array}$ & Serum acetaminophen level, urine toxicology screen \\
\hline & $\begin{array}{l}\text { Metabolic diseases (Wilson's disease, fatty acid } \\
\text { oxidation defects, mitochondrial defects, etc.) }\end{array}$ & $\begin{array}{l}\text { As above, plus serum Ceruloplasmin and 24-hr urine } \\
\text { copper. }\end{array}$ \\
\hline & $\begin{array}{l}\text { Infectious causes (hepatitis } \mathrm{A}, \mathrm{B}, \mathrm{C}, \mathrm{D}, \mathrm{E} \text {, non-A, } \\
\text { non-B viral hepatitis, EBV, CMV, enterovirus, } \\
\text { adenovirus, HHV-6, parvovirus, etc.) }\end{array}$ & As above \\
\hline & Autoimmune hepatitis & $\begin{array}{l}\text { Antinuclear antibody, anti-smooth muscle antibody, } \\
\text { anti-liver-kidney microsome antibody }\end{array}$ \\
\hline \multirow[t]{4}{*}{ Adolescent } & $\begin{array}{l}\text { Drug toxicity, toxin ingestion, accidental or intentional } \\
\text { drug overdose (acetaminophen, tetracycline, ecstasy, } \\
\text { toxic mushroom Amanita phalloides poisoning, etc.) }\end{array}$ & As above \\
\hline & Autoimmune hepatitis & \\
\hline & Wilson's disease and other metabolic diseases & \\
\hline & $\begin{array}{l}\text { Infectious diseases (hepatitis A, B, C, D, E, non-A, } \\
\text { non-B viral hepatitis, EBV, CMV, etc.) }\end{array}$ & \\
\hline
\end{tabular}

$H S V$, herpes simplex virus; $E B V$, Epstein-Barr virus; $C M V$, cytomegalovirus; $H H V$-6, human herpesvirus 6; $A S T$, aspartate aminotransferase; $A L T$, alanine aminotransferase; $G G T$, gamma glutamyl transferase; $P T-I N R$, prothrombin time and international normalized ratio; $a P T T$, activated partial thromboplastin time; $P C R$, polymerase chain reaction; $H A V$, hepatitis A virus; $H B s A g$, hepatitis B surface antigen; $H C V$, hepatitis $\mathrm{C}$ virus; $H E V$, hepatitis $\mathrm{E}$ virus; $T I B C$, total iron binding capacity 
Table 2 Complications in PALF

\begin{tabular}{|c|c|}
\hline Organ system & Complications \\
\hline Central nervous system & $\begin{array}{l}\text { - Hepatic encephalopathy } \\
\text { - Cerebral edema } \\
\text { - Intracranial hypertension }\end{array}$ \\
\hline Cardiovascular & $\begin{array}{l}\text { - Hypotension secondary to intravascular volume depletion } \\
\text { - Volume-refractory hyperdynamic circulatory failure }\end{array}$ \\
\hline Respiratory & $\begin{array}{l}\text { - Acute respiratory failure } \\
\text { - Pulmonary edema } \\
\text { - Pulmonary hemorrhage } \\
\text { - Acute respiratory distress syndrome (ARDS) } \\
\text { - Endotracheal intubation and mechanical } \\
\quad \text { ventilation-associated complications }\end{array}$ \\
\hline Renal & $\begin{array}{l}\text { - Acute kidney injury (AKI) } \\
\text { - Hepatorenal syndrome }\end{array}$ \\
\hline Adrenal & $\begin{array}{l}\text { - Relative adrenal insufficiency (RAI) } \\
\text { - Hepatoadrenal syndrome }\end{array}$ \\
\hline Hematological & $\begin{array}{l}\text { - Coagulopathy not corrected by Vitamin K administration } \\
\text { - Disseminated intravascular coagulopathy (DIC) }\end{array}$ \\
\hline Gastrointestinal & - Gastrointestinal bleeding \\
\hline Infectious & $\begin{array}{l}\text { - Systemic inflammatory response syndrome (SIRS) } \\
\text { - Pulmonary, urinary, and hematologic infections with bacteria } \\
\text { such as staphylococci, streptococci, and enteric } \\
\text { gram-negative bacteria }\end{array}$ \\
\hline Fluid, electrolytes, and nutrition & $\begin{array}{l}\text { - Hypoglycemia } \\
\text { - Hyperammonemia } \\
\text { - Intravascular volume depletion } \\
\text { - Alkalosis and acidosis } \\
\text { - Hyponatremia } \\
\text { - Hypokalemia } \\
\text { - Hypophosphatemia, hypocalcemia, hypomagnesemia } \\
\text { - Catabolic state with negative nitrogen balance and increased } \\
\text { energy expenditure }\end{array}$ \\
\hline
\end{tabular}

This gut-derived ammonia then enters the urea cycle where it is detoxified and excreted by the kidneys. The ammonia that bypasses the urea cycle is then converted to glutamine in astrocytes, skeletal myocytes, and hepatocytes. Astrocytes, the predominant type of cells in the brain, are very sensitive to rapid increase in serum levels of ammonia which, in turn, cause increase in intracellular glutamine concentration, leading to increased osmotic gradient and influx of water into the astrocytes resulting in cerebral edema (CE) and, subsequently, intracranial hypertension $(\mathrm{ICH})[2 \bullet \bullet, 13]$. Plasma concentration of ammonia does not always consistently correlate with the clinical manifestations of $\mathrm{HE}$ [14]. Increase in circulatory pro-inflammatory cytokines, especially interleukin IL-1 $\beta$ and IL-6 and tumor necrosis factor, can cause changes to cerebral blood flow and endothelial permeability affecting the development of $\mathrm{HE}$ and $\mathrm{CE}$ [15]. The incidence of CE and ICH is partially related to the severity of hepatic encephalopathy. About $55 \%$ of children developed HE in the PALF study group, $75 \%$ of which were grade 1 and 2 encephalopathies [3]. Grade 3 and 4 encephalopathies were observed in about 17 and $7 \%$ patients, respectively [3].

Management of Hepatic Encephalopathy Hepatic encephalopathy is managed with aggressive supportive care. Early diagnosis and prompt management of the same is critical to avoid progression to $\mathrm{CE}$ and ICH. Patients should be monitored closely with frequent neurological examinations. Patients should be minimally stimulated and unnecessary interventions should be avoided. Endotracheal intubation should be performed for airway protection and protected ventilation. Elevation of head end of the bed helps improve CSF drainage [16]. Fever and shivering may lead to increased intracranial pressure and should be treated aggressively. Lactulose and other antibiotics like rifaximin and 
neomycin are commonly used ammonia-lowering strategies used to treat HE; however, data to support this use in ALF is currently lacking [17]. L-Ornithine L-aspartate (LOLA) and L-ornithine phenyl acetate (LOPA) are currently being studied for use as ammonia-lowering agents by increasing the renal excretion of the same. These have shown promising results in the adult STOP-ALF trial [18]; however, there is no data regarding their use in PALF. A recent cohort study on ALF patients in US ALF Study group registry demonstrated the benefit of continuous renal replacement therapy (CRRT) in reduction of serum ammonia and improvement in 21-day transplant-free survival [19].

\section{Management of Intracranial Hypertension and Cerebral} Edema The goal in management of intracranial hypertension (ICH) and cerebral edema (CE) is lowering intracranial pressure (ICP) while preserving cerebral perfusion pressure (CPP) $[2 \bullet \bullet, 9]$. Clinical monitoring can be very difficult in pediatric patients with grades III-IV of HE. Cushing's triad (irregular breathing, systemic hypertension, and bradycardia), a sign of $\mathrm{ICH}$, is not uniformly present. Intracranial pressure monitoring allows assessment of CPP (difference between ICP and mean arterial pressure) which helps avoid hypoxic brain injury [9]. There have been multiple studies to assess safety and efficacy of invasive intracranial pressure monitoring. There has been no demonstrated improvement in survival with invasive intracranial pressure monitoring [20-22]. Invasive intracranial monitoring carries the risk of intracranial hemorrhage which can be fatal in these patients with coagulopathy [23]. The use of invasive ICP monitoring has not been studied in children and its use in PALF remains controversial. [2••].

Osmotic agents like hypertonic saline (HTS) and mannitol are amongst the principal therapies to reduce cerebral edema [24]. HTS (3-30\%) reduces ICP by decreasing cerebral water content by its osmotic effect and improves cerebral blood flow by reducing endothelial swelling by dehydration [25]. As a result, HTS has now been accepted as standard of care in management of ICH in children with traumatic brain injury [26]. In an RCT from King's College, the patients who received HTS had decreased ICP from baseline in the first $24 \mathrm{~h}$ and incidence of ICP $>25 \mathrm{mmHg}$ was also significantly lower when compared to standard care [27]. HTS has been studied and is currently recommended as a prophylactic agent to prevent ICP in adults at highest risk for cerebral edema [9]. Target serum sodium level should be maintained between 145 and $150 \mathrm{mmol} / \mathrm{L}[2 \bullet \bullet, 27]$. HTS has not been studied as an agent to treat acute increase in ICP in ALF patients. HTS is associated with electrolyte abnormalities, hyperchloremic metabolic acidosis, worsening coagulopathy, deep venous thrombosis, and hemorrhages $[25,28,29]$.

Mannitol has been used as a first-line agent to treat increased ICP in adults with ALF [9, 17]. Mannitol is a hyperosmolar agent and acts by increasing serum osmolality which leads to movement of water from the swollen astrocytes into serum. The current recommendation is to administer $0.25-1.0 \mathrm{~g} / \mathrm{kg}$ IV bolus, which can be repeated once or twice as long as serum osmolality remains less than $320 \mathrm{mOsm} / \mathrm{L}$ [9, 17]. Mannitol use has only been recommended for acute increase in ICP and it should not be used prophylactically [9]. Effect of mannitol is transient and it should not be used if serum osmolality is $>320 \mathrm{mOsm} / \mathrm{L}$, or in the presence of hypovolemia, or renal failure. Volume overload can occur with mannitol and might necessitate dialysis [2••, 9, 17]. Most of the information on use of mannitol is extrapolated from adult literature, and there are no controlled trials to assess the same in PALF.

Neurological morbidity is a major predictor of outcome for patients with ALF. Early identification of declining neurological status will allow earlier therapeutic interventions and help minimize morbidity and mortality [2••]. Seizure activity increases cerebral oxygen requirements and in patients with ALF may worsen cerebral edema [30]. Hussain et al. [31•] reported the role of EEG in management of PALF in their single-center retrospective study consisting of 19 children. Clinical seizures occurred in about $11 \%$ of patients and subclinical seizures were found in about $5 \%$ of patients. There was increased mortality in patients with EEG findings of moderate to severe slowing, epileptiform discharge, and electrographic seizure [31•]. EEG maybe used as a sensitive tool to screen for declining neurological status or subclinical seizures especially for patients with grade III or IV encephalopathy or clinical deterioration $[31 \cdot 32]$. Head imaging with computerized tomography $(\mathrm{CT})$ scan has been frequently used in patients who progress to stage III/IV HE or in patients with acute change in mental status to rule out different causes like intracranial hemorrhage and infections [33]. In a recent pediatric study, CT and magnetic resonance imaging (MRI) were abnormal in $13 \%$ of the patients but failed to demonstrate consistent abnormalities indicating the presence of cerebral edema [31•]. Also, there was no association between EEG and CT/MRI findings in these patients [31•]. A small retrospective study in adults demonstrated promising results for the use of transcranial Doppler waveform to assess the state of cerebral perfusion [34]. Prophylactic phenytoin has been used in adults with ALF to suppress subclinical seizures [32] but no overt benefit has been demonstrated in prevention of cerebral edema, in prevention of seizures, or in improvement in survival [30]. There is insufficient pediatric data to support the use of prophylactic antiepileptic agents in management of PALF $[2 \bullet \bullet]$.

Therapeutic hypothermia $\left(32^{\circ}-35^{\circ}\right)$ has been shown to reduce cerebral edema by decreasing ammonia level, attenuating inflammation and oxidative stresses in brain, and restoration of normal regulation of cerebral hemodynamics [35, 36]. Multiple systemic side effects like increased risk of infection, electrolyte disturbances and cardiac dysrhythmias, and 
coagulopathy have been associated with use of this modality of therapy $[35,36]$. There have been studies demonstrating the use of hypothermia for successful bridging of adult ALF patients to liver transplantation [12]. There is also a conflicting study demonstrating no difference in 21-day mortality and transplant-free survival between patients who received therapeutic hypothermia and those who did not [37]. There is no data in PALF to support the use of therapeutic hypothermia; active normothermia $\left(36^{\circ}-37^{\circ}\right)$, with aggressive management of hyperthermia, is the current standard of recommendation in management of PALF $[2 \cdot \bullet]$.

Hyperventilation reduces intracranial pressure by causing vasoconstriction. According to the most recent AASLD guidelines for management of ALF, there is no role for prophylactic hyperventilation in these patients, but patients with ALF hyperventilate spontaneously and this should not be inhibited [9].

There is insufficient data regarding agents to be used for sedation and/or analgesia in PALF. In general, short-acting agents, with dose adjustments for drugs metabolized in the liver, are preferred. Level of sedation should be carefully considered with special attention to potential benefit of anxiolytics versus the risk of masking signs of neurological deterioration or exacerbating encephalopathy. Benzodiazepines can

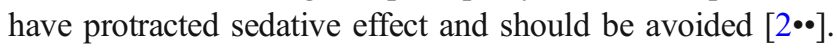
Recovery time from propofol is shorter and it may lower ICP by decreasing cerebral blood flow [38]. Propofol can be used in small doses for short periods in children without mitochondrial diseases $[2 \bullet \bullet]$. Concurrent use of opioid analgesics with short half-life, like fentanyl or remifentanil, can help reduce the dose of anesthetics and improve cardiovascular stability $[2 \cdot \bullet, 17]$. Atracurium and cisatracurium are preferred agents for neuromuscular blockade in children with ALF [39]. Vecuronium and rocuronium should be avoided as they undergo hepatic metabolism [39].

Cardiovascular Acute liver failure leads to peripheral vasodilatory response secondary to elevated cytokine release. This is associated with low systemic vascular resistance and low mean arterial pressures which contribute to decreased peripheral tissue oxygenation and can contribute to multiorgan failure. Most patients with ALF present with depleted intravascular volume due decreased oral intake and transudation of fluid into the extra-vascular spaces. As with any other hemodynamically compromised patient, resuscitation should start with adequate volume replacement with intravenous normal saline in these patients [9]. If the patient continues to be hypotensive after adequate fluid resuscitation, vasoconstrictor medications should be initiated. In adults, norepinephrine has been the preferred agent as it best enhances peripheral organ perfusion while minimizing tachycardia and preserving splanchnic circulation [17]. Despite the lack of pediatric data, norepinephrine is the rational choice of vasoconstrictor in volume-refractory hyperdynamic circulatory failure in PALF to ensure adequate central perfusion pressure (CPP) [2••]. Vasopressin and its analogs can be used to potentiate the effect of norepinephrine on patients who do not respond to the combination of volume challenge and norepinephrine [9].

Respiratory Patients with PALF may develop acute respiratory failure due to sepsis, pulmonary edema secondary to fluid overload, pulmonary hemorrhage, or acute respiratory distress syndrome (ARDS). About $20-30 \%$ of adult patients in ALF have been diagnosed with ARDS, but the incidence in PALF is unknown [40]. Endotracheal intubation may be required in PALF for acute respiratory failure resulting from abovementioned causes, or for airway protection subsequent to hepatic encephalopathy. About $40 \%$ of patients in the prospective PALF study required some type of ventilator support [41]. The strategies for mechanical ventilation in PALF must aim at balancing the risk of ventilator-associated lung injury and neuroprotection in the setting of increased ICP. It is suggested to maintain low tidal volumes and moderately elevated positive end expiratory pressure to maintain normal oxygenation [42]. Hyperventilation can be used in acute management of increased intracranial pressure not controlled with mannitol or other strategies mentioned above to delay impending cerebral herniation, but sustained hyperventilation should be avoided [9]. The standard of care in ventilating patients with increased ICP is maintaining normocapnia and avoiding hypoxemia.

Renal Acute kidney injury is a common occurrence in adults with ALF and has been associated with increased mortality. In a retrospective review of 1604 patients enrolled in Acute Liver Failure Study Group, 70\% patients demonstrated some degree of kidney injury, and AKI was observed in $45 \%$ patients. Overall survival as well as transplant-free survival for patients with AKI was decreased compared to those without AKI (57 vs. $93 \%$ and 37 vs. $64 \%$ respectively) [43]. The exact incidence of AKI in PALF is unknown. It is estimated that $17.5 \%$ children with ALF have associated AKI. AKI is associated with increased risk of mortality independent of respiratory failure or cerebral edema [44]. In the prospective PALF study involving 348 children with PALF, approximately $10-20 \%$ of patients required hemofiltration support but incidence of AKI or renal failure was not specified [41].

Functional renal failure or acute kidney injury in ALF is multifactorial and related to intrarenal vasoconstriction leading to decreased renal perfusion - a mechanism similar to hepatorenal syndrome in chronic liver failure [2••]. Acetaminophen-induced kidney injury, nephrotoxic medications, hypovolemia, sepsis, and acute tubular necrosis form the most common causes of AKI in ALF [45, 46]. Serum creatinine (SCr), urine output, and fluid balance are most frequently used for assessment of renal function in children. The change in SCr over the baseline is more pertinent to estimating renal injury than a single $\mathrm{SCr}$ value $[46,47]$. 
Prevention of hepatorenal syndrome is the focus of therapies used in management of AKI in PALF. These measures include adequate fluid resuscitation, avoiding excessive diuresis, avoiding volume overload, minimizing the use of nephrotoxic medications or intravenous contrast, and maintaining adequate renal perfusion pressure $[9,17$, 45]. Patients with suspected prerenal azotemia should receive an intravenous fluid challenge, but volume overload can be detrimental in patients with ALF [2••]. The criteria for the use of renal replacement therapy (RRT) in PALF are ill-defined. CRRT has been shown to decrease serum ammonia levels and increase 21-day transplant-free survival in adults with ALF [19]. It can also prevent worsening acidosis and fluid overload. The degree of renal dysfunction, metabolic derangements, and electrolyte disturbances help make the decision to start RRT [2••]. Continuous forms of renal replacement therapy (hemofiltration or dialysis) are preferred over intermittent forms to avoid the hemodynamic instabilities and the risk of increased ICP associated with the later $[9,48]$.

AKI in PALF usually resolves with normalization of liver function or after liver transplantation (LT). Adult indications for simultaneous liver/kidney transplantation are based on degree and duration of renal failure/kidney injury and/or duration of renal replacement therapy, typically after 8 to 12 weeks of dialysis [49]. There is insufficient data to define indications for simultaneous liver/kidney transplant in children [50•,51].

Adrenal Relative adrenal insufficiency (RAI) has been described in septic shock [52]. Impaired adrenal function in septic shock can depress the sensitivity to noradrenaline and this can be improved by administering physiologic doses of hydrocortisone [53]. Low HDL levels and increased levels of circulating endotoxins (i.e., lipopolysaccharides) and pro-inflammatory markers like tumor necrosis factor- $\alpha$ lead to impaired cortisol synthesis [54]. This leads to adrenal insufficiency in ALF, also known as hepatoadrenal syndrome. The incidence of hepatoadrenal syndrome correlates with severity of ALF [55]. Children with ALF are also at-risk for hepatoadrenal syndrome and vasopressor-dependent children in ALF may benefit from systemic corticosteroid administration [56, 57]. However, more research is required to make any definite recommendations. The consensus is that a trial of systemic steroids should be considered in patients with persistent shock resistant to both fluid resuscitation and vasopressor support [17].

Fluid, Electrolytes, and Nutrition Metabolic, electrolytes, and acid-base imbalances are common in PALF and need to be identified and corrected meticulously. ALF is a catabolic state with negative nitrogen balance with increased energy expenditure [58]. As a result, caloric requirements increase by about $20 \%$ in patients with ALF [58]. Unfortunately, due to lack of adequate studies, there are no clear guidelines on nutritional support in ALF. Nutritional regimen in PALF should be tailored to provide adequate calories, glucose, and protein to overcome catabolism while maintaining euglycemia and preventing hyperammonemia. Most of the recommendations regarding formula choice are targeted at chronic liver diseases or liver cirrhosis [59]. Enteral nutrition with high caloric density feeds should be pursued whenever possible to avoid excess free water administration which may exacerbate cerebral edema [17]. Parenteral nutrition is a safe second-line option in patients in whom adequate nutrition cannot be provided with enteral feeding [60]. Branchedchain amino acids provide no additional benefit over standard amino acid solutions [61]. Intravenous lipid solutions are used as a source of calories but it is important to recognize that fat metabolism may be problematic in some disorders such as mitochondrial diseases [62].

Electrolyte and acid-base disturbances are common in patients with PALF. Frequent monitoring and prompt correction of these abnormalities are critical to improve morbidity and mortality in these patients. Continuous glucose infusion at rates as high as $10-15 \mathrm{mg} / \mathrm{kg} / \mathrm{min}$ is necessary to maintain euglycemia in these patients [2••]. Both alkalosis and acidosis can occur. Sodium, potassium, phosphorus, calcium, and magnesium levels are frequently low and need to be corrected meticulously. Hyponatremia and hypokalemia can occur secondary to aggressive fluid resuscitation, ascites, and renal wasting with the use of diuretics. Avoiding hyponatremia is very critical to avoid worsening cerebral edema. [2••, 9].

Hematology-Coagulopathy INR $>1.5$ with encephalopathy or INR $>2.0$ without encephalopathy is required for diagnosis for ALF. Prolonged PT-INR is due to decrease in pro- and anticoagulant factors and is a marker for decreased synthetic function of the liver [2*0]. Platelets can also be low in these patients. Despite these clinical abnormalities, clinically significant bleeding is only seen in $<5 \%$ of patients, and spontaneous intracranial bleeding happens in $<1 \%$ of patients [63]. Newer techniques like thromboelastography have been found to be better at assessing the risk of bleeding but are not widely available for regular use [64]. Vitamin K deficiency is present in about $18-24 \%$ of adults with ALF and administration of IV vitamin $\mathrm{K}$ is recommended [65]. Plasma and/or platelet transfusions have their own drawbacks like transfusion-related lung injury and volume overload in addition to masking the elevation of INR which is a prognostic marker in ALF. Replacement of these blood products is only recommended prior to invasive procedures or in the setting of hemorrhage [9]. However, plasma infusion might not be adequate to correct severe coagulopathy and might risk volume overload. Use of recombinant factor VIIa (rFVIIa) has been found to be transiently effective in managing the coagulopathy and facilitates performance of invasive procedures and management of spontaneous hemorrhage without increasing the risk of volume overload [66]. 
This may be especially important in the setting of renal insufficiency. However, rFVIIa should be used cautiously mainly due to its high cost and reports of serious thromboembolic events associated with its administration [67].

Gastrointestinal Clinically significant bleeding is rare even with the degree of coagulopathy in patients with ALF [63]. The AASLD guidelines recommend H2 blockers or proton pump inhibitors for prophylaxis of stress-induced acid-related gastrointestinal bleeding in ICU-admitted patients with ALF [9]. Ascites might develop in a small number of patients with ALF. Spironolactone is the diuretic of choice and diuresis should be used only in patients with respiratory compromise or discomfort due to fluid accumulation as aggressive diuresis can precipitate hepatorenal syndrome in these patients [3].

Infections-SIRS The liver is involved in a variety of different immune-related functions. Patients with acute liver failure can have defects in many different mechanisms of host defense, making them more susceptible to infections. In a retrospective study of 887 adults with ALF, about $10-80 \%$ patients experienced bacterial infections with $10-37 \%$ attributable mortality $[68,69]$. In the same study, $56.8 \%$ patients demonstrated systemic inflammatory response syndrome (SIRS) [69]. The presence of one or more components of SIRS in patients with ALF was associated with increased mortality and worsening encephalopathy [69]. The magnitude of this was even greater when infection was present [69]. Data regarding SIRS or infection-related outcomes in PALF are currently lacking $[2 \bullet \bullet]$.

The guidelines regarding use of prophylactic antimicrobials or antifungals remain unclear [9, 17]. There are several adult studies investigating the role of prophylactic antibiotics in ALF, but the results remain inconclusive [37, 68-70]. Lungs, followed by urinary tract and blood, are the most common sites of bacterial infection, and gram-positive cocci (Staphylococci, Streptococci) and enteric gram-negative bacilli are the commonly isolated organisms [68]. Urine and blood cultures as well as chest X-rays are of paramount importance in surveillance for these infections [2••]. Empiric antibiotics are indicated in the presence of SIRS, worsening encephalopathy, refractory hypotension, or signs of infection [17] (Table 3).

\section{Liver Transplantation}

Liver transplantation offers a life-saving alternative to medical management in patients with PALF who have otherwise guarded prognosis. Timely liver transplantation has improved survival in patients with PALF. Currently, the indications and criteria for transplant are ill-defined and the process of listing for transplantation in PALF has not been streamlined [2••]. Between 2013 and 2015, about $10 \%$ of all pediatric liver transplants performed in the USA were performed on patients with PALF [4•]. According to the AASLD practice guidelines for evaluation of the pediatric patient for liver transplantation, it is recommended to establish an etiology for PALF in order to recognize conditions that can be treatable without LT or are contraindicated for LT [71••]. Uncontrolled sepsis, irreversible cerebral edema with uncal herniation, and severe multisystem mitochondrial disease are some contraindications for LT in PALF [71••].

Several prognostic scoring systems like the King's College Hospital Criteria (KCHC) and the Model for End-Stage Liver Disease (MELD) score have been validated and are routinely used in adult patients [72, 73]. The sequential organ failure assessment (SOFA) score has been used as triage marker for liver injury but has not been sufficiently validated to allow decision making for transplantation [74]. KCHC has been extensively used in adults with ALF. PALF study group used their database to validate $\mathrm{KCHC}$ criteria in non-acetaminophen-induced PALF patients. The sensitivity and positive predictive value for use of KCHC in PALF were significantly lower than those in the original study and it did not reliably predict death in PALF [75]. The Pediatric End-stage Liver Disease (PELD) score, incorporating albumin, bilirubin, INR, growth failure, and age ( $<1$ year), has been used as a predictor of mortality in children with chronic liver disease listed for transplantation, but it has not been extensively studied for use in PALF [76]. Another pediatric scoring system, pediatric Liver Injury Unit (LIU) score, may prove to be a helpful dynamic tool for prediction of outcomes in PALF. It uses peak values of total bilirubin and PT/INR during hospitalization to assess the risk of death or need of liver transplantation in PALF [77, 78].

Liver transplantation for ALF is generally associated with poor outcome when compared to that for chronic liver disease. In SPLIT database, the 1-year patient survival after transplant was $74 \%$ for PALF compared to $88.2 \%$ of other conditions [79]. The factors predicting poor outcome following liver transplantation were age $<1$ year, grade IV encephalopathy, and need for dialysis prior to transplantation [79]. In a single-center study involving 122 PALF patients from the University of California, Los Angeles, 1 -, 5-, and 10-year patient survivals was 81,77 , and $73 \%$ respectively [80]. Poor renal function as indicated by low creatinine clearance and less than 7 days between onset of jaundice and encephalopathy were indicators for poor patient survival and low creatinine clearance, age less than 24 months, and PELD/MELD score greater than 25 were associated with increased graft loss [80]. 
Table 3 Management of PALF

\begin{tabular}{|c|c|}
\hline Problem & Management \\
\hline Hyperammonemia & $\begin{array}{l}\text { - Consider lactulose and other antibiotics like rifaximin and neomycin (insufficient data to } \\
\text { support use in ALF) } \\
\text { - Ammonia-lowering agents like LOLA and LOPA are under investigation } \\
\text { - Consider continuous renal replacement therapy }\end{array}$ \\
\hline Hepatic encephalopathy & $\begin{array}{l}\text { - Supportive care in ICU } \\
\text { - Minimal stimulation; avoid unnecessary interventions } \\
\text { - Endotracheal intubation especially for stage } 3 \text { or } 4 \text { encephalopathy } \\
\text { - Consider CT/MRI head for any acute mental status changes }\end{array}$ \\
\hline Intracranial hypertension/cerebral edema & $\begin{array}{l}\text { - HTS }(3-30 \%) \text { to maintain target serum Na level to } 145 \text { to } 150 \mathrm{mmol} / \mathrm{L} \text { can be used as } \\
\text { prophylaxis to prevent ICP and CE } \\
\text { - Mannitol } 0.25-1.0 \mathrm{~g} / \mathrm{kg} \text { IV bolus, repeated once or twice if serum osmolality } \\
<320 \mathrm{mOsm} / \mathrm{L} \\
\text { - Invasive intracranial monitoring is currently controversial and not routinely } \\
\text { recommended in PALF }\end{array}$ \\
\hline Cardiovascular instability & $\begin{array}{l}\text { - Adequate fluid resuscitation with IV normal saline } \\
\text { - Norepinephrine is the preferred choice of vasoconstrictor agent for } \\
\text { volume-refractory instability } \\
\text { - Vasopressin and its analogs can be used to potentiate the effect of norepinephrine }\end{array}$ \\
\hline Respiratory failure & $\begin{array}{l}\text { - Endotracheal intubation should be performed for respiratory failure or for airway } \\
\text { protection in advanced stages of hepatic encephalopathy } \\
\text { - Ventilator strategies include low tidal volumes }(5-8 \mathrm{ml} / \mathrm{kg} \text { of predicted weight) and } \\
\text { moderately elevated PEEP levels } \\
\text { - Sustained hyperventilation should be avoided }\end{array}$ \\
\hline Acute kidney injury/hepatorenal syndrome & $\begin{array}{l}\text { - Preventive measures include maintaining fluid balance while avoiding excessive diuresis, } \\
\text { minimizing the use of nephrotoxic medications or IV contrast, and maintaining renal } \\
\text { perfusion pressure } \\
\text { - Continuous renal replacement therapy is preferred over intermittent forms }\end{array}$ \\
\hline Relative adrenal insufficiency/hepatoadrenal syndrome & $\begin{array}{l}\text { - Trial of systemic steroids can be considered in patients with persistent shock refractory to } \\
\text { volume resuscitation and vasopressor support }\end{array}$ \\
\hline Coagulopathy & $\begin{array}{l}\text { - Plasma or platelet transfusions are only recommended prior to invasive procedure or } \\
\text { during active bleeding }\end{array}$ \\
\hline Ascites & $\begin{array}{l}\text { - Spironolactone is the diuretic of choice for patients with ascites who have respiratory } \\
\text { compromise or discomfort due to fluid accumulation }\end{array}$ \\
\hline Gastrointestinal bleed & $\begin{array}{l}\text { - H2 blocker or proton pump inhibitors are recommended for prophylaxis } \\
\text { of gastrointestinal bleed }\end{array}$ \\
\hline Infection/SIRS & $\begin{array}{l}\text { - Use of prophylactic antimicrobials or antifungals is currently controversial and is not } \\
\text { routinely recommended } \\
\text { - Aggressive surveillance with cultures and empiric antibiotics are indicated in the presence } \\
\text { of SIRS, worsening encephalopathy, refractory hypotension, or signs of infection }\end{array}$ \\
\hline Nutrition, hypoglycemia & $\begin{array}{l}\text { - Enteral nutrition with high caloric density formula to avoid excess free water } \\
\text { - Parenteral nutrition can be a safe second line choice in patients who cannot be fed enterally } \\
\text { - Continuous glucose infusion at } 10-15 \mathrm{mg} / \mathrm{kg} / \mathrm{min} \text { might be necessary to maintain } \\
\text { euglycemia in these patients }\end{array}$ \\
\hline Electrolytes & $\begin{array}{l}\text { - Frequent monitoring and correction of electrolytes and acid-base balance is critical } \\
\text { - Avoiding hyponatremia is critical to prevent cerebral edema in these patients }\end{array}$ \\
\hline
\end{tabular}

HTS, hypertonic saline; SIRS, systemic inflammatory response syndrome

Conclusion Management of PALF challenges our skills as physicians and intensivists. There have been promising improvements in outcomes over last few decades due to numerous recent advances in intensive care management of PALF. However, the current management of PALF still remains supportive and is either based on adult data and/or experience from local institutions. PALF remains poorly defined and incompletely studied due to its rarity and heterogeneity. Future studies designed by hepatologists and intensivists, and targeted towards improved etiological diagnosis, refined prognostic indicators, and potential for a medical cure, should be prioritized. Intensive supportive care, systematic diagnostic approach, and early transfer to transplant center with timely liver transplantation are the current best approach to improve outcomes in patients with PALF.

\section{Compliance with Ethical Standards}

Conflict of Interest The authors declare that they have no conflicts of interest.

Human and Animal Rights and Informed Consent This article does not contain any studies with human or animal subjects performed by any of the authors. 


\section{References}

Papers of particular interest, published recently, have been highlighted as:

- Of importance

- Of major importance

1. Liver disease in children. In: Suchy FJ, Sokol RJ, Balistreri WF, editors. 4th ed. ed. Cambridge: Cambridge University Press; 2014.

2.• Lutfi R, Abulebda K, Nitu ME, Molleston JP, Bozic MA, Subbarao G. Intensive care management of pediatric acute liver failure. J Pediatr Gastroenterol Nutr. 2017;64(5):660-70. https://doi.org/10. 1097/mpg.0000000000001441. This article is the most recent publication outlining practical aspects of clinical care in pediatric acute liver failure. As evident by this article, there is a very high need of well-designed studies in the field of pediatric acute liver to help manage the same.

3. Squires RH Jr. Acute liver failure in children. Semin Liver Dis. 2008;28(2):153-66. https://doi.org/10.1055/s-2008-1073115.

4. Kim WR, Lake JR, Smith JM, Skeans MA, Schladt DP, Edwards EB, et al. OPTN/SRTR 2015 Annual Data Report: liver. Am J Transplant. 2017;17:174-251. https://doi.org/10.1111/ajt.14126. Most recent data report on liver transplantation in the USA.

5. Narkewicz MR, Dell Olio D, Karpen SJ, Murray KF, Schwarz K, Yazigi N, et al. Pattern of diagnostic evaluation for the causes of pediatric acute liver failure: an opportunity for quality improvement. J Pediatr. 2009;155(6):801-6.e1. https://doi.org/10.1016/j. jpeds.2009.06.005.

6. Sundaram SS, Alonso EM, Narkewicz MR, Zhang S, Squires RH. Characterization and outcomes of young infants with acute liver failure. J Pediatr. 2011;159(5):813-8.e1. https://doi.org/10.1016/j. jpeds.2011.04.016.

7. Schwarz KB, Olio DD, Lobritto SJ, Lopez MJ, Rodriguez-Baez N, Yazigi NA, et al. Analysis of viral testing in nonacetaminophen pediatric acute liver failure. J Pediatr Gastroenterol Nutr. 2014;59(5):616-23.

8. Bucuvalas J, Yazigi N, Squires RH Jr. Acute liver failure in children. Clin Liver Dis. 2006;10(1):149-68, vii. https://doi.org/10. 1016/j.cld.2005.10.006.

9. Lee WM, Larson AM, Stravitz RT. AASLD position paper: the management of acute liver failure: update 2011. AASLD September. 2011.

10. Singhal A, Vadlamudi S, Stokes K, Cassidy FP, Corn A, Shrago SS, et al. Liver histology as predictor of outcome in patients with acute liver failure. Transpl Int. 2012;25(6):658-62. https://doi.org/10. 1111/j.1432-2277.2012.01470.x.

11. Ostapowicz G, Fontana RJ, Schiodt FV, Larson A, Davern TJ, Han $\mathrm{SH}$, et al. Results of a prospective study of acute liver failure at 17 tertiary care centers in the United States. Ann Intern Med. 2002;137(12):947-54.

12. Jalan R, Olde Damink SW, Hayes PC, Deutz NE, Lee A. Pathogenesis of intracranial hypertension in acute liver failure: inflammation, ammonia and cerebral blood flow. J Hepatol. 2004;41(4):613-20. https://doi.org/10.1016/j.jhep.2004.06.011.

13. Scott TR, Kronsten VT, Hughes RD, Shawcross DL. Pathophysiology of cerebral oedema in acute liver failure. World J Gastroenterol. 2013;19(48):9240-55. https://doi.org/10.3748/ wjg.v19.i48.9240.

14. Bernal W, Hall C, Karvellas CJ, Auzinger G, Sizer E, Wendon J. Arterial ammonia and clinical risk factors for encephalopathy and intracranial hypertension in acute liver failure. Hepatology (Baltimore, Md). 2007;46(6):1844-52. https://doi.org/10.1002/ hep. 21838 .
15. Butterworth RF. The concept of "the inflamed brain" in acute liver failure: mechanisms and new therapeutic opportunities. Metab Brain Dis. 2016;31(6):1283-7. https://doi.org/10.1007/s11011015-9747-0.

16. Feldman Z, Kanter MJ, Robertson CS, Contant CF, Hayes C, Sheinberg MA, et al. Effect of head elevation on intracranial pressure, cerebral perfusion pressure, and cerebral blood flow in headinjured patients. J Neurosurg. 1992;76(2):207-11. https://doi.org/ 10.3171/jns.1992.76.2.0207.

17. Stravitz RT, Kramer AH, Davern T, Shaikh AO, Caldwell SH, Mehta RL, et al. Intensive care of patients with acute liver failure: recommendations of the U.S. Acute Liver Failure Study Group. Crit Care Med. 2007;35(11):2498-508. https://doi.org/10.1097/ 01.ccm.0000287592.94554.5f.

18. Stravitz RT, Gottfried M, Durkalski V, Fontana RJ, Hanje AJ, Koch D, et al. Safety, Tolerability and pharmacokinetics of 1-ornithine phenylacetate in patients with acute liver injury/failure and hyperammonemia. Hepatology (Baltimore, Md). 2017; https://doi. org/10.1002/hep.29621.

19. Cardoso FS, Gottfried M, Tujios S, Olson JC, Karvellas CJ. Continuous renal replacement therapy is associated with reduced serum ammonia levels and mortality in acute liver failure. Hepatology (Baltimore, Md). 2017; https://doi.org/10.1002/hep.29488.

20. Kamat P, Kunde S, Vos M, Vats A, Gupta N, Heffron T, et al. Invasive intracranial pressure monitoring is a useful adjunct in the management of severe hepatic encephalopathy associated with pediatric acute liver failure. Pediatr Crit Care Med. 2012;13(1):e33-8. https://doi.org/10.1097/PCC.0b013e31820ac08f.

21. Rajajee V, Fontana RJ, Courey AJ, Patil PG. Protocol based invasive intracranial pressure monitoring in acute liver failure: feasibility, safety and impact on management. Crit Care (London, England). 2017;21(1):178. https://doi.org/10.1186/s13054-0171762-6.

22. Vaquero J, Fontana RJ, Larson AM, Bass NM, Davern TJ, Shakil AO, et al. Complications and use of intracranial pressure monitoring in patients with acute liver failure and severe encephalopathy. Liver Transpl. 2005;11(12):1581-9. https://doi.org/10.1002/lt.20625.

23. Blei AT, Olafsson S, Webster S, Levy R. Complications of intracranial pressure monitoring in fulminant hepatic failure. Lancet (London, England). 1993;341(8838):157-8.

24. Richardson D, Bellamy M. Intracranial hypertension in acute liver failure. Nephrol Dial Transplant. 2002;17(1):23-7.

25. Doyle JA, Davis DP, Hoyt DB. The use of hypertonic saline in the treatment of traumatic brain injury. J Trauma. 2001;50(2):367-83.

26. Bell MJ, Kochanek PM. Pediatric traumatic brain injury in 2012: the year with new guidelines and common data elements. Crit Care Clin. 2013;29(2):223-38. https://doi.org/10.1016/j.ccc.2012.11.004.

27. Murphy N, Auzinger G, Bernel W, Wendon J. The effect of hypertonic sodium chloride on intracranial pressure in patients with acute liver failure. Hepatology (Baltimore, Md). 2004;39(2):464-70. https://doi.org/10.1002/hep.20056.

28. Qureshi AI, Suarez JI. Use of hypertonic saline solutions in treatment of cerebral edema and intracranial hypertension. Crit Care Med. 2000;28(9):3301-13.

29. Webster DL, Fei L, Falcone RA, Kaplan JM. Higher-volume hypertonic saline and increased thrombotic risk in pediatric traumatic brain injury. J Crit Care. 2015;30(6):1267-71. https://doi.org/10. 1016/j.jcrc.2015.07.022.

30. Bhatia V, Batra Y, Acharya SK. Prophylactic phenytoin does not improve cerebral edema or survival in acute liver failure - a controlled clinical trial. J Hepatol. 2004;41(1):89-96. https://doi.org/ 10.1016/j.jhep.2004.03.017.

31. Hussain E, Grimason M, Goldstein J, Smith CM, Alonso E, Whitington PF, et al. EEG abnormalities are associated with increased risk of transplant or poor outcome in children with acute liver failure. J Pediatr Gastroenterol Nutr. 2014;58(4):449-56. 
https://doi.org/10.1097/mpg.0000000000000271. Recent singlecenter retrospective study for role of EEG in children with acute liver failure.

32. Ellis AJ, Wendon JA, Williams R. Subclinical seizure activity and prophylactic phenytoin infusion in acute liver failure: a controlled clinical trial. Hepatology (Baltimore, Md). 2000;32(3):536-41. https://doi.org/10.1053/jhep.2000.9775.

33. McPhail MJ, Patel NR, Taylor-Robinson SD. Brain imaging and hepatic encephalopathy. Clin Liver Dis. 2012;16(1):57-72. https:// doi.org/10.1016/j.cld.2011.12.001.

34. Aggarwal S, Brooks DM, Kang Y, Linden PK, Patzer JF 2nd. Noninvasive monitoring of cerebral perfusion pressure in patients with acute liver failure using transcranial Doppler ultrasonography. Liver Transpl. 2008;14(7):1048-57. https://doi.org/10.1002/lt. 21499.

35. Stravitz RT, Larsen FS. Therapeutic hypothermia for acute liver failure. Crit Care Med. 2009;37(7 Suppl):S258-64. https://doi. org/10.1097/CCM.0b013e3181aa5fb8.

36. Vaquero J. Therapeutic hypothermia in the management of acute liver failure. Neurochem Int. 2012;60(7):723-35. https://doi.org/10. 1016/j.neuint.2011.09.006.

37. Karvellas CJ, Cavazos J, Battenhouse H, Durkalski V, Balko J, Sanders C, et al. Effects of antimicrobial prophylaxis and blood stream infections in patients with acute liver failure: a retrospective cohort study. Clin Gastroenterol Hepatol. 2014;12(11):1942-9.e1. https://doi.org/10.1016/j.cgh.2014.03.011.

38. Wijdicks EF, Nyberg SL. Propofol to control intracranial pressure in fulminant hepatic failure. Transplant Proc. 2002;34(4):1220-2.

39. Craig RG, Hunter JM. Neuromuscular blocking drugs and their antagonists in patients with organ disease. Anaesthesia. 2009;64(Suppl 1):55-65. https://doi.org/10.1111/j.1365-2044. 2008.05871.x

40. Audimoolam VK, McPhail MJ, Wendon JA, Willars C, Bernal W, Desai SR, et al. Lung injury and its prognostic significance in acute liver failure. Crit Care Med. 2014;42(3):592-600. https://doi.org/ 10.1097/01.ccm.0000435666.15070.d5.

41. Squires RH Jr, Shneider BL, Bucuvalas J, Alonso E, Sokol RJ, Narkewicz MR, et al. Acute liver failure in children: the first 348 patients in the pediatric acute liver failure study group. J Pediatr. 2006;148(5):652-8. https://doi.org/10.1016/j.jpeds.2005.12.051.

42. Khemani RG, Smith LS, Zimmerman JJ, Erickson S. Pediatric acute respiratory distress syndrome: definition, incidence, and epidemiology: proceedings from the Pediatric Acute Lung Injury Consensus Conference. Pediatr Crit Care Med. 2015;16(5 Suppl 1):S23-40. https://doi.org/10.1097/pcc.0000000000000432.

43. Tujios SR, Hynan LS, Vazquez MA, Larson AM, Seremba E, Sanders CM, et al. Risk factors and outcomes of acute kidney injury in patients with acute liver failure. Clin Gastroenterol Hepatol. 2015;13(2):352-9. https://doi.org/10.1016/j.cgh.2014.07.011.

44. Kulkarni S, Perez C, Pichardo C, Castillo L, Gagnon M, BeckSague C, et al. Use of Pediatric Health Information System database to study the trends in the incidence, management, etiology, and outcomes due to pediatric acute liver failure in the United States from 2008 to 2013. Pediatr Transplant. 2015;19(8):888-95. https:// doi.org/10.1111/petr.12596.

45. Leventhal TM, Liu KD. What a nephrologist needs to know about acute liver failure. Adv Chronic Kidney Dis. 2015;22(5):376-81. https://doi.org/10.1053/j.ackd.2015.06.006.

46. Moore JK, Love E, Craig DG, Hayes PC, Simpson KJ. Acute kidney injury in acute liver failure: a review. Expert Rev Gastroenterol Hepatol. 2013;7(8):701-12. https://doi.org/10.1586/ 17474124.2013.837264.

47. Fortenberry JD, Paden ML, Goldstein SL. Acute kidney injury in children: an update on diagnosis and treatment. Pediatr Clin N Am. 2013;60(3):669-88. https://doi.org/10.1016/j.pcl.2013.02.006.
48. Davenport A. Continuous renal replacement therapy for liver disease. Hemodial Int. 2003;7(4):348-52. https://doi.org/10.1046/j. 1492-7535.2003.00061.x.

49. Nadim MK, Sung RS, Davis CL, Andreoni KA, Biggins SW, Danovitch GM, et al. Simultaneous liver-kidney transplantation summit: current state and future directions. Am J Transplant Off J Am Soc Transplant Am Soc Transplant Surg. 2012;12(11):2901-8. https://doi.org/10.1111/j.1600-6143.2012.04190.x.

50. Elizabeth Parsons C, Nelson R, Book LS, Kyle Jensen M. Renal replacement therapy in infants and children with hepatorenal syndrome awaiting liver transplantation: a case-control study. Liver Transpl. 2014;20(12):1468-74. https://doi.org/10.1002/lt.23987. Recent case-control study stressing the importance of CRRT in children with hepatorenal syndrome.

51. Jalanko H, Pakarinen M. Combined liver and kidney transplantation in children. Pediatr Nephrol (Berlin, Germany). 2014;29(5): 805-14; quiz 12. https://doi.org/10.1007/s00467-013-2487-7.

52. Annane D, Sebille V, Charpentier C, Bollaert PE, Francois B, Korach JM, et al. Effect of treatment with low doses of hydrocortisone and fludrocortisone on mortality in patients with septic shock. JAMA. 2002;288(7):862-71.

53. Annane D, Bellissant E, Sebille V, Lesieur O, Mathieu B, Raphael $\mathrm{JC}$, et al. Impaired pressor sensitivity to noradrenaline in septic shock patients with and without impaired adrenal function reserve. Br J Clin Pharmacol. 1998;46(6):589-97.

54. Marik PE, Gayowski T, Starzl TE. The hepatoadrenal syndrome: a common yet unrecognized clinical condition. Crit Care Med. 2005;33(6):1254-9.

55. Tsai MH, Peng YS, Chen YC, Liu NJ, Ho YP, Fang JT, et al. Adrenal insufficiency in patients with cirrhosis, severe sepsis and septic shock. Hepatology (Baltimore, Md). 2006;43(4):673-81. https://doi.org/10.1002/hep.21101.

56. Hauser GJ, Brotzman HM, Kaufman SS. Hepatoadrenal syndrome in pediatric patients with end-stage liver disease. Pediatr Crit Care Med. 2012;13(3):e145-9. https://doi.org/10.1097/PCC. 0b013e31822flb9e.

57. Soltys KA, Mazariegos GV. Hepatoadrenal syndrome in critically ill children with liver failure: is it true, true, and unrelated? Pediatr Crit Care Med. 2012;13(3):366-7. https://doi.org/10.1097/PCC. 0b013e318238b286.

58. Walsh TS, Wigmore SJ, Hopton P, Richardson R, Lee A. Energy expenditure in acetaminophen-induced fulminant hepatic failure. Crit Care Med. 2000;28(3):649-54.

59. Plauth M, Cabre E, Riggio O, Assis-Camilo M, Pirlich M, Kondrup $J$, et al. ESPEN Guidelines on Enteral Nutrition: liver disease. Clin Nutr (Edinburgh, Scotland). 2006;25(2):285-94. https://doi.org/10. 1016/j.clnu.2006.01.018.

60. Plauth M, Cabre E, Campillo B, Kondrup J, Marchesini G, Schutz T, et al. ESPEN Guidelines on Parenteral Nutrition: hepatology. Clin Nutr (Edinburgh, Scotland). 2009;28(4):436-44. https://doi. org/10.1016/j.clnu.2009.04.019.

61. Gluud LL, Dam G, Les I, Marchesini G, Borre M, Aagaard NK, et al. Branched-chain amino acids for people with hepatic encephalopathy. Cochrane Database Syst Rev. 2017;5:Cd001939. https:// doi.org/10.1002/14651858.CD001939.pub4.

62. Schutz T, Bechstein WO, Neuhaus P, Lochs H, Plauth M. Clinical practice of nutrition in acute liver failure - a European survey. Clin Nutr (Edinburgh, Scotland). 2004;23(5):975-82. https://doi.org/10. 1016/j.clnu.2004.03.005.

63. Munoz SJ, Stravitz RT, Gabriel DA. Coagulopathy of acute liver failure. Clin Liver Dis. 2009;13(1):95-107. https://doi.org/10.1016/ j.cld.2008.10.001.

64. Agarwal B, Wright G, Gatt A, Riddell A, Vemala V, Mallett S, et al. Evaluation of coagulation abnormalities in acute liver failure. J Hepatol. 2012;57(4):780-6. https://doi.org/10.1016/j.jhep.2012.06.020. 
65. Pereira SP, Rowbotham D, Fitt S, Shearer MJ, Wendon J, Williams R. Pharmacokinetics and efficacy of oral versus intravenous mixedmicellar phylloquinone (vitamin K1) in severe acute liver disease. J Hepatol. 2005;42(3):365-70. https://doi.org/10.1016/j.jhep.2004. 11.030 .

66. Shami VM, Caldwell SH, Hespenheide EE, Arseneau KO, Bickston SJ, Macik BG. Recombinant activated factor VII for coagulopathy in fulminant hepatic failure compared with conventional therapy. Liver Transpl. 2003;9(2):138-43. https://doi.org/10. 1053/jlts.2003.50017.

67. Pavese P, Bonadona A, Beaubien J, Labrecque P, Pernod G, Letoublon $\mathrm{C}$, et al. FVIIa corrects the coagulopathy of fulminant hepatic failure but may be associated with thrombosis: a report of four cases. Can J Anaesth. 2005;52(1):26-9. https://doi.org/10. 1007/bf03018576.

68. Rolando N, Harvey F, Brahm J, Philpott-Howard J, Alexander G, Gimson A, et al. Prospective study of bacterial infection in acute liver failure: an analysis of fifty patients. Hepatology (Baltimore, Md). 1990;11(1):49-53

69. Rolando N, Wade J, Davalos M, Wendon J, Philpott-Howard J, Williams R. The systemic inflammatory response syndrome in acute liver failure. Hepatology (Baltimore, Md). 2000;32(4 Pt 1): 734-9. https://doi.org/10.1053/jhep.2000.17687.

70. Rolando N, Gimson A, Wade J, Philpott-Howard J, Casewell M, Williams R. Prospective controlled trial of selective parenteral and enteral antimicrobial regimen in fulminant liver failure. Hepatology (Baltimore, Md). 1993;17(2):196-201.

71.• Squires RH, Ng V, Romero R, Ekong U, Hardikar W, Emre S, et al. Evaluation of the pediatric patient for liver transplantation: 2014 practice guideline by the American Association for the Study of Liver Diseases, American Society of Transplantation and the North American Society for Pediatric Gastroenterology, Hepatology, and Nutrition. J Pediatr Gastroenterol Nutr. 2014;59(1):112-31. https://doi.org/10.1097/mpg. 0000000000000431 . Most recent guidelines for evaluation of children for liver transplantation.

72. Dhiman RK, Jain S, Maheshwari U, Bhalla A, Sharma N, Ahluwalia $\mathrm{J}$, et al. Early indicators of prognosis in fulminant hepatic failure: an assessment of the Model for End-Stage Liver
Disease (MELD) and King's College Hospital criteria. Liver Transpl. 2007;13(6):814-21. https://doi.org/10.1002/lt.21050.

73. McPhail MJ, Wendon JA, Bernal W. Meta-analysis of performance of Kings's College Hospital Criteria in prediction of outcome in non-paracetamol-induced acute liver failure. J Hepatol. 2010;53(3):492-9. https://doi.org/10.1016/j.jhep.2010.03.023.

74. Cholongitas E, Theocharidou E, Vasianopoulou P, Betrosian A, Shaw S, Patch D, et al. Comparison of the sequential organ failure assessment score with the King's College Hospital criteria and the model for end-stage liver disease score for the prognosis of acetaminophen-induced acute liver failure. Liver Transpl. 2012;18(4):405-12. https://doi.org/10.1002/lt.23370.

75. Sundaram V, Shneider BL, Dhawan A, Ng VL, Im K, Belle S, et al. King's College Hospital Criteria for non-acetaminophen induced acute liver failure in an international cohort of children. J Pediatr. 2013;162(2):319-23.e1. https://doi.org/10.1016/j.jpeds.2012.07.002.

76. Barshes NR, Lee TC, Udell IW, O'Mahoney CA, Karpen SJ, Carter $\mathrm{BA}$, et al. The pediatric end-stage liver disease (PELD) model as a predictor of survival benefit and posttransplant survival in pediatric liver transplant recipients. Liver Transpl. 2006;12(3):475-80. https://doi.org/10.1002/lt.20703.

77. Lu BR, Gralla J, Liu E, Dobyns EL, Narkewicz MR, Sokol RJ. Evaluation of a scoring system for assessing prognosis in pediatric acute liver failure. Clin Gastroenterol Hepatol. 2008;6(10):1140-5. https://doi.org/10.1016/j.cgh.2008.05.013.

78. Lu BR, Zhang S, Narkewicz MR, Belle SH, Squires RH, Sokol RJ. Evaluation of the liver injury unit scoring system to predict survival in a multinational study of pediatric acute liver failure. J Pediatr. 2013;162(5):1010-6.e1-4. https://doi.org/10.1016/j. jpeds.2012.11.021.

79. Baliga P, Alvarez S, Lindblad A, Zeng L. Posttransplant survival in pediatric fulminant hepatic failure: the SPLIT experience. Liver Transpl. 2004;10(11):1364-71. https://doi.org/10.1002/lt.20252.

80. Farmer DG, Venick RS, McDiarmid SV, Duffy JP, Kattan O, Hong JC, et al. Fulminant hepatic failure in children: superior and durable outcomes with liver transplantation over 25 years at a single center. Ann Surg. 2009;250(3):484-93. https://doi.org/10.1097/SLA. 0b013e3181b480ad. 